\section{Were crocodiles responsible for the stones we call tools?}

SIR - Could Nature have been unknowingly publishing papers for the past 80 years about crocodilian gastroliths (stomach stones) instead of stones concluded to be 2.5-million-yearold hominid tools? This possibility could cast doubt, for example, on the nature of the Oldowan specimens described by Michael Haslam and colleagues in their Review of primate archaeology (Nature 460, 339-344; 2009).

Palaeontologists use a simple eyeball test to distinguish stone tools from gastroliths. If a specimen has wear marks on its outer surface but none on its inner surfaces, this indicates that the stone has been grinding away in some prehistoric stomach or other and is a gastrolith. But wear on both inner and outer surfaces indicates that it has been used for some sort of pounding or battering and can confidently be considered a tool. A quick look at the three Oldowan specimens reveals wear on only the extended surfaces, so they should be considered as gastroliths, not tools.

Identification of the Oldowan specimens as tools is based on the fact that the soft relict sands of Olduvai Gorge contain no natural stones of their own, so any stone found there must have been moved from distant river beds by some unknown animal transporter - concluded by high science to be Homo habilis.

But crocodiles have the curious habit of swallowing rocks: these account for $1 \%$ of their body weight, so for a 1-tonne crocodile that's $10 \mathrm{~kg}$ of stones in its stomach at all times. Surprisingly, science has never even considered the crocodile as transporter.

Crocodiles and hippos have always lived happily together. Hippo herds would naturally trample riverside gravel stones into the shape of Oldowan cutting tools, quantities of which the

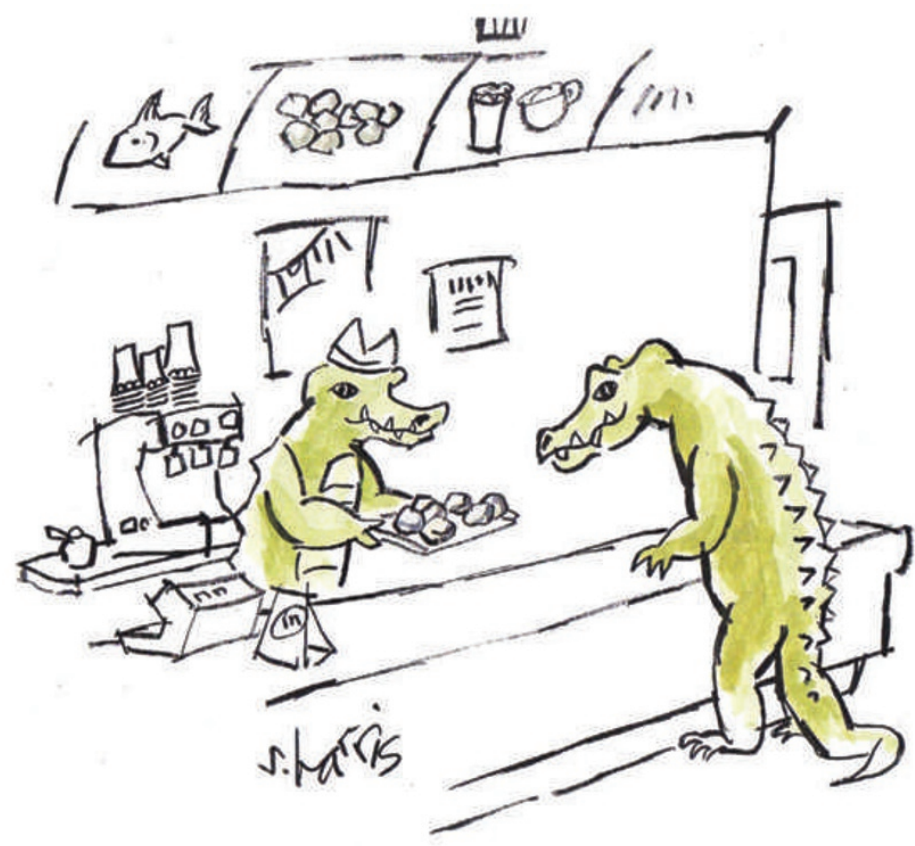

prohibited in several. But ethical standards may differ and/or change in the near future. The implications should be borne in mind by researchers everywhere in their impulse to follow up any application of tetraploid complementation technology with human iPS cells.

Hans-Werner Denker Institut für Anatomie, Universität Duisburg-Essen, Hufelandstrasse 55, 45122 Essen, Germany e-mail: hans-werner.denker@ uni-due.de

\section{The need for a fresh symbol to designate copernicium}

SIR - There could be a question mark hanging over the symbol proposed for the newly recognized element 112, copernicium (Nature 460, 449; 2009).

According to the current recommendations of the International Union of Pure and Applied Chemistry on naming new elements, a candidate name cannot be reused on another element (W. H. Koppenol Pure Appl. Chem. 74, 787-791; 2002). For example, the names hahnium or joliotium can no longer be considered for any as-yet unnamed element, because both were once used to name element 105 , which is now called dubnium.

If this rule is formally extended to symbols of elements, it will affect the proposed symbol (Cp) for copernicium. This symbol was used for element 71, cassiopeium, before that was formally named lutetium (F. A. Paneth Nature 159, 8-10; 1947).

With $\mathrm{C}, \mathrm{Ce}, \mathrm{Cm}, \mathrm{Co}, \mathrm{Cr}$ and $\mathrm{Cu}$ already taken, $\mathrm{Ci}$ short for curie as a unit of radioactivity and $C p$ open to debate, a 'clean' option for copernicium could be the unprecedented Cc.

Juris Meija Institute for National Measurement Standards, National Research Council Canada, Government of Canada, 1200 Montreal Road M-12, B-16 Ottawa, Ontario K1A OR6, Canada e-mail: juris.meija@nrc-cnrc.gc.ca 